\title{
RELATOS DE PESQUISAS \\ DO CAMPO DE SISTEMAS DE INFORMAÇÃO NO BRASIL: UM ESTUDO DOS ANAIS DO ENANPAD (2010-2018) NOS SEUS ASPECTOS TEÓRICOS, METODOLÓGICOS E EPISTEMOLÓGICOS
}

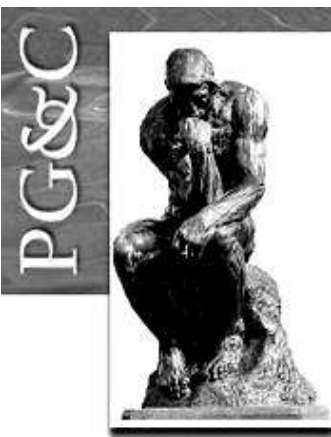

\author{
André Felipe de Albuquerque Fell \\ Doutor em Administração pela Universidade Federal de Pernambuco, \\ Brasil. Professor da Universidade Federal de Pernambuco, Brasil. \\ E-mail: highland97@hotmail.com
}

\begin{abstract}
Resumo
Buscou-se avaliar o estado da arte do campo de Sistemas de Informação (SI) no Brasil, a partir da análise dos trabalhos publicados nos anais do Encontro Anual da Associação Nacional de Pós-Graduação e Pesquisa em Administração (Enanpad) de 2010 a 2018 nos seus aspectos teóricos, metodológicos e epistemológicos. Para tal, fez-se uma pesquisa documental de natureza quali-quantitativa em 28 artigos acadêmicos publicados na Divisão Acadêmica de Administração da Informação (ADI - tema 07, mudando em 2018, para ADI - tema 06) do Enanpad no período em tela. Em termos de resultados, observou-se que teoricamente há uma pluralidade de perspectivas teóricas sendo aplicadas ao campo de SI; metodologicamente, notou-se o predomínio de artigos empíricos (78,57\%); a abordagem de pesquisa mais adotada como sendo a de natureza qualitativa (50\%) e as estratégias de pesquisa concentradas mais em cinco tipos: ensaio $(21,43 \%)$, estudo bibliométrico $(17,85 \%)$, survey $(10,71 \%)$, revisão sistemática+bibliométrico $(10,71 \%)$ e estudo de casos múltiplos $(7,14 \%)$. Em termos epistemológicos, ainda é significativa a presença do paradigma positivista $(60,7 \%)$, o que pode indicar ainda alguma resistência ao uso de métodos interpretativos em SI como, por exemplo, o método hermenêutico dialético, ou a hermenêutica crítica (HC), de Myers (1995); ou ainda, o uso da análise crítica do discurso, usando Habermas (CUKIER et al., 2009).
\end{abstract}

Palavras-chave: Gestão de Sistemas de Informação. Sistemas de Informação. Anais do Enanpad.

\section{THE INFORMATION SYSTEMS FIELD IN BRAZIL: A STUDY OF ENANPAD'S PAPERS (2010-2018) CONCERNING ITS THEORETICAL, METHODOLOGICAL AND EPISTEMOLOGICAL ASPECTS}

\begin{abstract}
This research aimed to evaluate the state of art of Information Systems (IS) field in Brazil by analyzing papers published at Enanpad (2010-2018), concerning its theoretical, methodological and epistemological aspects. Therefore a documental, qualitative-quantitative research was done on 28 papers from Academic Division of Information Management (IM - theme 7, changing in 2018 to IM theme 6) at Enanpad (2010-2018). In outcomes terms, a variety of theoretical perspectives are being applied to IS field in Brazil. Methodologically, there was a predominance of empirical papers (78,57\%); a predominance of qualitative approaches (50\%) and research strategies focused in five types: essays $(21,43 \%)$, bibliometric studies $(17,85 \%)$, survey $(10,71 \%)$, systematic review + bibliometric $(10,71 \%)$. and multiple case studies $(7,14 \%)$. Finally, in epistemological terms, positivist paradigm has a significant presence $(60,70 \%)$ among national papers studied, which may still show some reluctance in using interpretative methods in IS, like dialetic hermeneutical method, or Myers (1995) critical hermeneutics (CH), or even still, critical discourse analysis based on Habermas (CUKIER et. al., 2009).
\end{abstract}

Keywords: Information Systems Management. Information Systems. Enanpad's papers.

Perspectivas em Gestão \& Conhecimento, João Pessoa, v. 10, n. 2, p. 180-202, maio/ago. 2020. DOI: http://dx.doi.org/10.21714/2236-417X2020v10n2p180

http://periodicos.ufpb.br/ojs2/index.php/pgc. ISSN: 2236-417X. Publicação sob Licença (cc) EY-NC-ND 


\section{INTRODUÇÃO}

A área de Gestão de Sistemas de Informação (GSI), ou apenas Sistemas de Informação (SI) como é conhecida atualmente, vem se desenvolvendo e tomando forma gradativamente como campo de pesquisa desde a década de 1960. Para Davis e Olson (1985), essa área constitui uma junção entre a Ciência da Computação; Administração e Teoria Organizacional; Pesquisa Operacional e Contabilidade. Cada uma dessas disciplinas, apesar de sua orientação abrangente, trouxe contribuições específicas para o uso de computadores na realidade organizacional. Curiosamente, nenhuma dessas disciplinas, em particular, abordou de modo específico a aplicação de computadores nas organizações. Em seus estudos, Hirschheim e Klein (2012) acrescentam que além das disciplinas mencionadas, o desenvolvimento da área de SI tem recebido significativa influência de disciplinas como Teoria de Sistemas, Cibernética, Economia da Informação; além de áreas tão diversas quanto a Psicologia, Antropologia, Economia, Sociologia, Ciência Política, Filosofia e Arquitetura.

É possível notar o crescimento da área de SI ao longo de mais de quatro décadas, quer no surgimento de novas especializações, grupos de pesquisa ampliando significativamente o nível das investigações; ou ainda, através de novos periódicos, departamentos, conferência, literatura, etc. (HIRSCHHEIM; KLEIN, 2012). No geral, a literatura em SI pode ser identificada como diversa e plural; o que alguns autores denominam de "harmonia plural" (KING et. al., 2010). Tal diversidade, para alguns estudiosos é considerada uma bênção (ROBEY, 1996); já para outros, uma maldição (BENBASAT; WEBER, 1996). Independentemente da divergência de opiniões, a diversidade parece ser a característica distintiva da área de SI que representa o melhor consenso entre os estudiosos (ALAVI; CARLSON; BROOKE, 1989; KEEN, 1991; ORLIKOWSKI; BAROUDI, 1991; MARKUS, 1997; HIRSCHHEIM; KLEIN, 2003; KING; LYYTINEN, 2006; KLEIN; HIRSCHHEIM, 2008).

Com o crescimento do campo de SI, poder-se-ia imaginar que os seus estudiosos demarcaram uma forte atuação tanto na academia como na prática organizacional. Em realidade, tal fato não parece estar ocorrendo porque o campo de SI ainda enfrenta dificuldades quanto a sua identidade e legitimidade (CHECKLAND; HOLWELL, 1998; BENBASAT; ZMUD, 2003; GALLIERS, 2003; KING; LYYTINEN, 2006). Mesmo com mais de quatro décadas de sua concepção, os pesquisadores em SI ainda questionam "o que aconteceria se o campo de SI deixasse de existir?" (MARKUS, 1999) ou "será que o campo de SI está em crise?" (HIRSCHHEIM; KLEIN, 2003). Daí o esforço de alguns estudiosos da área em buscarem respostas para "o que é SI?" e "de que modo SI difere de outras disciplinas como Ciência da Computação e Administração?" (BACKHOUSE; LIEBENAU; LAND, 1991).

É importante ressaltar que pesquisadores pioneiros em SI como Blumenthal (1969), Davis (1974), Langefors (1974) e Land (1975) tentaram desenvolver ideias e conceitos explicativos para SI. A inexistência de qualquer consenso, explica porque até hoje se tem grandes dificuldades em dizer o que é e o que não é SI; justificando a multiplicidade de terminologias para categorizar o campo: TI (Tecnologia da Informação); Informática; Gestão de Sistemas de Informação (GSI); Gestão da Informação (GI) e Ciência da Informação (CI) (AVGEROU; SIEMER; BJORN-ANDERSEN, 1999; DAVIS, 2000). Se por um lado essa multiplicidade pode demonstrar força e flexibilidade de um campo aberto a diversas ideias (ROBEY, 1996; DAVIS, 2000); por outro, pode ocasionar trabalhos com temas frequentemente desconexos (BJORN-ANDERSEN, 1984; BENBASAT; WEBER, 1996). Isso quando não acontece de o campo ser visto como desorganizado (LUCAS, 1999) e ser questionado se as suas pesquisas têm contribuído para uma tradição de acúmulo de pesquisa (KEEN, 1980). Ademais, o campo de SI com uma fronteira móvel ou fluída apresenta o risco de ser disperso em outras disciplinas, em particular nas das escolas de negócios (LUCAS, 1999). Como exemplo, pode-se mencionar que a localização institucional para a área de SI nos EUA está comumente vinculada

Perspectivas em Gestão \& Conhecimento, João Pessoa, v. 10, n. 2, p. 180-202, maio/ago. 2020. 
às escolas de Administração; enquanto que na Europa, essa institucionalização é bem mais diversificada, encontrando-se associada tanto a departamentos de Engenharia ou Ciências Exatas, quanto a outros ligados às Ciências Sociais (AVGEROU, 2000).

Houve ainda pesquisadores que tentaram categorizar as fronteiras das pesquisas em $\mathrm{SI}$ a partir de modelos elaborados (GORRY; SCOTT-MORTON, 1971; MASON; MITROFF, 1973; IVES; HAMILTON; DAVIS, 1980). Ainda uma vez, uma profusão de conflitos entre os modelos propostos ao longo de diferentes períodos, gerou falta de um entendimento tácito das questões centrais ao campo SI (WAND; WEBER, 1990). Tais modelos representavam um esforço contínuo de definir e redefinir $\mathrm{SI}$, refletindo a expansão das fronteiras de estudos no campo e, por conseguinte, conduzindo os estudiosos a reconhecerem a impossibilidade de algum reducionismo na identidade da área, por mais que se buscasse isso. Diniz et. al. (2006, p. 2) reiteram essa ideia quando afirmam: "Os múltiplos aspectos sociais, culturais e tecnológicos presentes nas pesquisas no campo de SI são decorrentes das relações entre informação, organização e pessoas e definem um caráter complexo não só na definição e delimitação do objeto de pesquisa, mas também no uso consistente de instrumentos de pesquisa padronizados".

Assim, a despeito da ampliação quer dos conteúdos, das direções e das tendências no campo de SI, o aumento das oportunidades de pesquisa na área não parece estar sendo devidamente seguido por uma maior variedade de abordagens metodológicas (CIBORRA, 2002). O autor supracitado identificou que os métodos de pesquisa qualitativos têm sido praticamente marginalizados, com o predominante uso de métodos quantitativos, o que merece escrutínio a partir de pesquisas mais recentes. Se as questões metodológicas refletem as posturas epistemológicas adotadas pelos pesquisadores, explica-se a significativa presença de métodos quantitativos nas pesquisas em SI por causa da ênfase predominante de questões técnicas / racionalistas presentes nas investigações do campo (ORLIKOWSKI; BAROUDI, 1991; POZZEBON, 2003). Tal fato também acontece nas pesquisas em SI no Brasil, conforme identificaram os trabalhos de Hoppen et al. (1998); Rodrigues Filho et al. (1999) e Fell, Ximenes e Rodrigues Filho (2004); aqui também se ressaltando a importância de uma investigação e análise mais hodiernas. Neste contexto, o problema de pesquisa é: "como as atuais pesquisas realizadas no campo de SI no Brasil vem se desenvolvendo nos seus aspectos teóricos, metodológicos e epistemológicos?"

\section{JUSTIFICATIVA DE PESQUISA}

Pode-se afirmar que o estabelecimento da identidade de um campo de pesquisa acontece quando ele é capaz de contribuir com a formação de um sólido corpo de conhecimentos, a partir da criação de teorias gerais significativas acerca de seus conceitos teóricos centrais (POPPER, 1969; BENBASAT; ZMUD, 2003). Reforça-se essa identidade com o rigor aplicado às pesquisas desenvolvidas e a relevância dos temas de pesquisa para o mundo real (LEE, 1991; BENBASAT; ZMUD, 1999; LEE, 1999; RADEMACHER, 2001). Posteriormente, a identidade de um campo de pesquisa é mais fortalecida quando certos temas comuns caracterizam os problemas de pesquisa (BENBASAT; WEBER, 1996; ROBEY, 1996; WEBER, 2003; HIRSCHHEIM; KLEIN, 2003). Desse modo, a inexistência dos fatores centrais de rigor, relevância e temas comuns certamente dificultam bastante a institucionalização de um campo de pesquisa porque não ficam claros os resultados e as contribuições daquele campo; dificultando ainda a captação de recursos e o desenvolvimento de pesquisadores dispostos a seguirem carreira naquela área (KRISHNA, 2007).

Assim, justifica-se a presente pesquisa por representar um esforço de contribuição para conhecer o campo de SI no Brasil no que diz respeitos aos seus aspectos teóricos, metodológicos e epistemológicos e, eventualmente, contribuindo para incitar novas

Perspectivas em Gestão \& Conhecimento, João Pessoa, v. 10, n. 2, p. 180-202, maio/ago. 2020. 
oportunidades de pesquisa. Ademais, a escolha dos trabalhos publicados nos Enanpads (Encontro Anual da Associação Nacional de Pós-Graduação e Pesquisa em Administração) de 2010 a 2015 (posteriormente inclusos os trabalhos dos anos de 2016 a 2018, nesta mesma pesquisa), justifica-se porque é no âmbito da área de Administração de Informação do Enanpad que acontece o principal fórum para a divulgação e debate dos resultados no campo de SI no Brasil (HOPPEN; MEIRELLES, 2005).

\section{FUNDAMENTAÇÃO TEÓRICA}

\subsection{Um breve histórico de SI}

Desde o seu início, na década de 1960, a área de SI vem apresentando significativo progresso (DAVIS, 2000); indo de um esforço de se diferenciar da ciência da computação e outras disciplinas, até o atual estágio de reconhecimento como área própria. Aqui, será exposto de modo sucinto, o trabalho de Hirschheim e Klein (2012) que procurou organizar mais de 45 anos de história da área de SI em quatro grandes eras, não necessariamente divididas em períodos de igual duração: 1a ERA (meados de 1960 até meados de 1970); 2a ERA (meados de 1970 até meados de 1980); 3a ERA (meados de 1980 até o final de 1990) e a 4a ERA (final de 1990 até os dias atuais).

1a ERA: Aqui, as organizações mudaram o foco de simplesmente automatizarem os processos organizacionais básicos, na década de 1950 e início de 1960; para consolidarem determinado controle na função de processamento de dados. Para tal, as empresas centralizaram a função de sistemas de informação nas rotinas operacionais de processamento de dados, com alguma forma de gestão de inventário e sistemas de processamento de transações. Na maioria dos casos, essa função era exercida por um gerente de operações computacionais que se reportava ao controller contábil. Ademais, havia poucos usuários, estando a maioria concentrada nos departamentos de engenharia e contabilidade. Tecnologicamente essa era foi dominada pelo uso de mainframes pelas empresas, uma vez que possuíam maior capacidade de processar complexas transações organizacionais. Acontece que todo modelo novo de mainframe demandava novo hardware e novo software, o que significava dizer que os computadores se tornavam incompatíveis entre si. Isso mudou em 1964 quando a IBM lançou a família 360 de sistemas computacionais compatíveis. As séries 360 introduziram a noção de arquitetura uniforme e integrada de sistemas computacionais em toda a empresa e ressaltaram a importância do software que fosse compatível em diversas plataformas. Além disso, esse período foi caracterizado pelo desenvolvimento de novas tecnologias como o circuito integrado que permitiu que todos os circuitos de um mainframe pudessem ser implantados em um único chip; além da tecnologia do microprocessador, capaz de aumentar significativamente a capacidade de processamento dos computadores. Em termos de pesquisa, nessa era inexistia qualquer discussão sobre métodos de investigação; existiam sim, escolas de pensamento como as de C. West Churchman, Daniel Teichroew, Börje Langefors, Sherman Blumenthal, entre outros.

2a ERA: Os avanços tecnológicos continuaram a ocorrer, como com a introdução do computador pessoal $(\mathrm{PC}=$ personal computer). Com o PC, as organizações conseguiram expandir a sua capacidade computacional de processamento para todas as suas áreas uma vez que os custos de hardware para O PC tornaram-se significativamente menores quando comparados com o mainframe. Por outro lado, outras áreas diferentes da engenharia e contabilidade passaram a demandar o uso dos recursos disponibilizados pelo PC, aumentando assim a diversidade de usuários e conduzindo as empresas a uma orientação mais fortemente gerencial nas operações dos sistemas de informação, em detrimento da tradicional abordagem

Perspectivas em Gestão \& Conhecimento, João Pessoa, v. 10, n. 2, p. 180-202, maio/ago. 2020. 
técnica dos sistemas de informação. Apesar disso, não foi possível vislumbrar qualquer esforço de desenvolver um alinhamento entre as estratégias de negócios e os sistemas de informação porque os profissionais ou departamentos da área de tecnologia estavam desenvolvendo aplicativos importantes para os sistemas de informação específicos a sua área de atuação. Ressalta-se ainda que nessa era, havia organizações que buscavam envolver os usuários de SI nos projetos de desenvolvimento desses sistemas. Os usuários contribuíam na determinação dos requisitos dos aplicativos, bem como no monitoramento da viabilidade das entregas dos sistemas de informação ainda que a fase de desenvolvimento estivesse em andamento (DEMARCO, 1978; GANE; SARSON, 1979). Em termos de pesquisa, identificou-se na 2a era uma tentativa de definir o campo de SI. Em seus estudos, Ives, Hamilton e Davis (1980) definiram SI em termos de cinco ambientes (externo, organizacional, usuário, desenvolvimento de SI e operações de SI), três processos (usuário, desenvolvimento e operações de SI) e um subsistema informacional. Já Nolan e Wetherbe (1980, p. 5) definiram SI como "um sistema aberto (tecnologia) que transforma dados, requisições informacionais e recursos organizacionais (inputs) em informações (outputs) inseridas em um contexto organizacional (ambiente de gerenciamento de SI) e que viabiliza um sistema de feedback". A seu turno, Keen (1987) categorizou o campo de SI em termos de áreas de problemas que cada era histórica (dos anos de 1970 aos anos de 1980) decide se concentrar em um deles. Há que se observar que enquanto alguns pesquisadores procuravam definir $\mathrm{SI}$ a partir de diferentes áreas de investigação; outros pesquisadores optaram por buscar a identidade de SI através da identificação de disciplinas de referência. Como exemplos, Culnan (1986; 1987) e Culnan e Swanson (1986) desenvolveram análises de co-citação e constataram que o campo de SI costumava se referenciar a três categorias: princípios fundamentais (exemplo: ciência dos sistemas), disciplinas aplicadas relacionadas (exemplo: finanças, gestão) e as disciplinas de base (exemplo: psicologia, sociologia). Há que se ressaltar aqui que o foco das pesquisas que buscavam estudar o campo de SI foi muito além das pesquisas realizadas nas décadas de 1960 e 1970, uma vez que se buscava agora avaliar quais eram as contribuições do campo de SI e não apenas a identificação de áreas de pesquisa.

3a ERA: Essa era pode ser caracterizada pelas empresas buscando adquirir os hardwares e softwares que atendam às necessidades dos seus departamentos. Em outros termos, essa é a era do PC desencadeando a computação departamental, ou seja, a descentralização no uso dos sistemas de informação. Todavia, essa tendência causou novos problemas como a incompatibilidade de dados, além das questões de conectividade e integridade entre os departamentos organizacionais. Tecnologicamente, talvez o maior avanço dessa era foi o desenvolvimento em larga escala da computação em rede, quer no ambiente empresarial, quer no ambiente governamental, através do protocolo TCP/IP; abrindo caminho para o início da internet - que somente na era seguinte efetivamente mudaria o campo de SI. Quanto às pesquisas, verificou-se o desenvolvimento de novos tópicos de pesquisas, tais como: implantação de SI, o paradoxo da produtividade do SI, alinhamento estratégico e outsourcing. A corrente de pesquisa sobre a produtividade dos sistemas de informação (SIs) continuou a seguir a tradição dos anos 1980 de se basear nos estudos econômicos, o que significa dizer que os impactos organizacionais gerados pelos Sls eram mensurados pela performance econômica alcançada nas organizações que os adotavam (MAHMOOD; MANN, 1993; HITT; BRYNJOLFSSON, 1996). Além disso, havia pesquisadores que procuravam avaliar o valor do SI através de métricas de performance como o retorno sob investimento $(\mathrm{ROI}=$ Return on Investment) e participação no mercado (market share). Acontece que os resultados encontrados nessa área mostraram pouca relação entre investimentos em SI e melhoria de performance organizacional (BARUA; MURKHOPADHYAY, 2000). Tal fato levou Roach (1988; 1989) a elaborar a expressão "paradoxo da produtividade em tecnologia da informação" que de certo modo sintetizava os resultados conflitantes, isto é, o maciço investimento das

Perspectivas em Gestão \& Conhecimento, João Pessoa, v. 10, n. 2, p. 180-202, maio/ago. 2020. 
organizações em TI com a esperança de aumento de produtividade, mas que todavia, não se conseguia mensurar a performance da $\mathrm{TI}$ a ponto de afirmar que ela efetivamente aumentava a produtividade. As justificativas dos pesquisadores para esses resultados contraditórios residiam no fato de que as abordagens econômicas sobre SI não conseguiam apontar onde e de que modo os impactos do SI eram percebidos e nem conseguiam indicar as ações gerenciais capazes de incrementar os retornos de investimentos em SI (BARUA; KRIEBEL; MUKHOPADHYAY, 1995; BARUA; MUKHOPADHYAY, 2000). Ainda nessa era, outra perspectiva de análise do valor do SI para as organizações se desenvolveu concomitantemente e de modo independente à primeira. Ela desenvolveu uma orientação de modelo de processo, propondo uma abordagem multidimensional para a criação de valor aos sistemas de informação (KAUFMANN; KRIEBEL, 1988; BANKER; KAUFMANN, 1991). Essa perspectiva pode ser vista como complementar à abordagem economicista inicial. De modo específico, essa perspectiva analisa o impacto dos Sls e outros fatores organizacionais através de uma rede interrelacionada de diversas variáveis de interesse. É importante notar que a corrente de pesquisa sobre o valor dos sistemas de informação continua a ser desenvolvida hodiernamente e ainda é motivo de discórdias (STRASSMANN, 1985).

4a ERA: Essa era é marcada por uma significativa mudança tanto na tecnologia de SI quanto no ambiente organizacional porque a possibilidade de realizar transações comerciais pela internet ocasionou o desenvolvimento de novas formas de comunicação e condução dos negócios inexistentes nas eras anteriores. Foi a internet que permitiu, independentemente do tempo e local, a disseminação do conhecimento para os diversos cantos do mundo. Devido a isso, e às mudanças no ambiente competitivo, as organizações precisaram modificar as suas estratégias empresariais para aproveitarem as novas oportunidades que a tecnologia da internet estava disponibilizando. Houve ainda por parte das empresas uma mudança de foco no que diz respeito a oferta de melhores serviços e produtos personalizados aos clientes. A ampla e significativa presença e aceitação da tecnologia no ambiente dos negócios empresariais acabaram por se apresentar um grande desafio aos gestores de SI que agora precisavam administrar as tecnologias largamente distribuídas, assim como os profissionais de SI e os usuários. Assim, ao adentrarem o final de 1990, as organizações foram do foco de criar e desenvolver novas tecnologias para o de alcançarem uma massa crítica na era da internet (HEVNER; BERNDT; STUDNICKI, 2000) já que essa tecnologia modificava o ambiente competitivo ao permitir o constante estado de conectividade e comunicação com clientes e fornecedores a ponto de minimizar significativamente questões de tempo e local, - tão comuns no tradicional e obsoleto modelo de negócio bricks-and-mortar (tijolos e cimento). Para competirem com as organizações virtuais, muitas empresas precisaram realizar uma reengenharia em suas operações para se tornarem empresas interconectadas ou em rede e, por isso, desenvolveram intranets e extranets que deram suporte à reengenharia de seus processos. Quanto às pesquisas, muitos temas estudados nessa era eram extensões das eras anteriores. Com a fase comercial da internet, notou-se um quantitativo novo de correntes de pesquisas que iam desde o uso geral da internet até o uso específico da internet para os negócios empresariais (comércio eletrônico). Em outras palavras, esses estudos compreendiam a adoção do comércio eletrônico (TAN; TEO, 2000), assim como o valor e a performance da internet para as empresas (BAKOS; NAULT, 1997). Além disso, o amplo uso de mecanismos de busca ampliou significativamente as possibilidades de pesquisa sobre a otimização de mecanismos de busca (search engine optimization - SEO) e web analytics (análise de dados da internet). 


\subsection{A área acadêmica de SI no Brasil: uma breve exposição}

Reforçando o que já foi dito anteriormente, considera-se o campo acadêmico de SI preocupado com uma multifacetada gama de questões relacionadas ao desenvolvimento, uso e possíveis implicações da TI na realidade das organizações; não se enquadrando facilmente o seu objeto de estudos às convencionais categorias de disciplinas conhecidas porque muito embora esses estudos tenham forte relação com as novas tecnologias, há que se considerar em suas análises as questões relativas à ação organizacional e à mudança social (AVGEROU, 2000).

No Brasil, a área acadêmica de SI é relativamente jovem uma vez que surgiu na década de 1970 na Sucesu e na década seguinte nas escolas de Administração brasileiras. Hodiernamente, essa área recebe diversas denominações: Tecnologia da Informação (TI), Informática, Administração da Informação e, recentemente, Tecnologia da Informação e Comunicação (TEC) (HOPPEN; MEIRELLES, 2005). Sua origem, de um modo geral, ocorreu nos departamentos de Métodos Quantitativos ou de Administração da Produção.

Ainda na década de 1980, quatro programas de pós-graduação participaram de um intenso esforço inicial para consolidar um corpo de conhecimento em SI: a Escola de Administração de Empresas de São Paulo da Fundação Getúlio Vargas (FGV-EAESP), o Instituto Coppead de Administração da Universidade Federal do Rio de Janeiro (Coppead-UFRJ), a Faculdade de Administração e Economia da Universidade de São Paulo (FEA-USP) e o Programa de Pós-Graduação em Administração da Escola de Administração da Universidade Federal de Rio Grande do Sul (PPGA-UFRGS) (HOPPEN; MEIRELLES, 2005). Já na década de 1990, os principais programas de Pós-Graduação em Administração criaram os primeiros núcleos, centros ou linhas de pesquisa voltadas para SI. Ainda segundo Hoppen e Meirelles (2005), entre 1985 e 1995, foram criados grupos de pesquisa em Tecnologia da Informação, Gestão de Sistemas de Informação e Administração de Recursos de Informática. Na FGV-EAESP, constatou-se a fundação do CIA (Centro de Informática Aplicada); na FEA-USP foi criado um grupo voltado à Informática Pública e para SI, enquanto no PPGA-UFRGS foi fundado o GESID (Grupo de Estudos de Sistemas de Informação e Decisão). Ao final da década de 1990, foram incorporados a esses grupos, novos temas de pesquisa como o comércio eletrônico, negócios na era digital, sistemas integrados de gestão, planejamento e alinhamento estratégico, business intelligence, educação à distância e gestão do conhecimento.

Em termos de evento científico, a partir de 1988 foi criada a área de Administração da Informação do Enanpad com o objetivo de fomentar a geração e consolidação do conhecimento no campo de $\mathrm{SI}$, acompanhando e investigando novos desenvolvimentos e aplicações de sistemas, novas abordagens e novas metodologias de pesquisa em SI que venham a surgir tanto no Brasil como no exterior.

\subsection{Perspectivas teóricas, metodológicas e epistemológicas dos estudos em SI}

Nessa seção foram detalhadas as bases conceituais empregadas na análise dos dados, de modo a possibilitar o alcance do objetivo geral da pesquisa que foi avaliar o estado da arte do campo de conhecimento de SI no Brasil, em termos teóricos, metodológicos e epistemológicos, a partir da análise dos trabalhos publicados nos anais do Enanpad (2010 a 2018). Em termos mais específicos, nessa seção foram especificadas as contribuições de Hirschheim e Klein (2003) quanto aos conhecimentos presentes nos trabalhos analisados (técnico, normativo (ético), teórico e aplicado (prático)) e as contribuições de Orlikowski e Baroudi (1991) no que diz respeito aos aspectos epistemológicos (positivista, interpretativo e crítico) dos trabalhos estudados.

Perspectivas em Gestão \& Conhecimento, João Pessoa, v. 10, n. 2, p. 180-202, maio/ago. 2020. 
Em seus estudos, Hirschheim e Klein (2003) conseguiram estruturar o conhecimento em quatro tipos desenvolvidos a seguir:

- Conhecimento técnico: diz respeito a uma técnica determinada ou regras de habilidades, caracterizando visivelmente um conhecimento necessário para realizar operações especificadas com a finalidade de obtenção de um resultado razoavelmente bem definido. Esse conhecimento tipicamente aperfeiçoa ações racional-premeditadas.

- Conhecimento normativo (ético): diz respeito a valores morais considerados nas escolhas a serem feitas entre duas ou mais opções possíveis. Ele inclui tanto as teorias éticas quanto os casos em que a escolha precisa ser feita aplicando-se, algumas vezes, princípios de teorias éticas conflitantes.

- Conhecimento teórico: esse tipo de conhecimento está centrado na articulação de entendimentos, incluindo a compreensão das consequências da busca por ações, bem como o potencial de prever e elaborar hipóteses por vários modos de inferências e também na elaboração de modelos conceituais explicativos que auxiliem na organização de um vasto corpo de conhecimento.

- Conhecimento aplicado (prático): é o conhecimento demandado na resolução de problemas do cotidiano do trabalho ou da vida pessoal, por exemplo. É comumente referido como sabedoria ou conhecimento da experiência pessoal aplicada, apreendida, vivenciada. Pode ser visto como o conhecimento do senso comum.

Já para Orlikowski e Baroudi (1991), a pesquisa em SI pode assumir uma das seguintes categorias:

- Positivista: quando há evidência de proposições formais; medidas quantificáveis das variáveis; testes de hipóteses; além do delineamento de inferências em um fenômeno, partindo de uma amostra para uma população. Esses estudos são fundamentados na existência, a priori, de relações fixas, presentes ao fenômeno e que são investigadas por uma instrumentação estruturada. Basicamente, tais estudos procuram testar uma teoria.

- Interpretativa: procura compreender o fenômeno através dos significados que as pessoas atribuem a ele. A pesquisa interpretativa não define antecipadamente variáveis dependentes e independentes; seu foco é na inteira complexidade do processo humano de dar sentido às coisas na medida em que as situações acontecem (KAPLAN; MAXWELL, 1994). A base filosófica da pesquisa interpretativa é a hermenêutica e a fenomenologia (BOLAND, 1985).

- Crítica: entende que a realidade social é historicamente constituída através de um processo de construção e reconstrução feito pelas pessoas. Os pesquisadores críticos, apesar de reconhecerem que as pessoas podem conscientemente agir no sentido de modificarem suas circunstâncias sociais e econômicas, afirmam que essa habilidade para a mudança é constrangida por diversas formas de dominação social, cultural e política. Portanto, o principal desafio da pesquisa crítica é o da crítica social, na qual as condições restritivas e alienantes do status quo são trazidas à tona. A pesquisa crítica focaliza as resistências, os conflitos e as contradições da sociedade contemporânea, visando à emancipação e eliminação das causas de alienação e dominação.

\section{PROCEDIMENTOS METODOLÓGICOS E MATERIAL DE ESTUDO}

O presente estudo pode ser considerado uma pesquisa documental, caracterizando-se como de natureza quali-quantitativa. Ele é quantitativo por se utilizar de elementos da estatística descritiva simples. E também é qualitativo por valorizar a natureza interpretativa das análises e por se acreditar que o entendimento mais aprofundado de um fenômeno só é possível de ser alcançado através de uma pesquisa interpretativa (ORLIKOWSKI; BAROUDI, 1991; WALSHAM, 1995).

Perspectivas em Gestão \& Conhecimento, João Pessoa, v. 10, n. 2, p. 180-202, maio/ago. 2020. 
A unidade de análise é formada por 28 artigos acadêmicos publicados na Divisão Acadêmica de Administração da Informação (ADI - tema 07, mudando em 2018, para ADI tema 06) do Enanpad no período de 2010 a 2018. Tal intervalo se justifica pelo aspecto de acessibilidade aos artigos publicados. É importante ressaltar que o tema 07 (2010 a 2017) e tema 06 (2018) da ADI, sob a mesma denominação "Visão do campo e aspectos teóricos e metodológicos em TI/SI", conforme o site do Enanpad (2018), trata de

[...] discutir a área de pesquisa de $\mathrm{TI} / \mathrm{SI}$, oportunidades de pesquisa, novas tendências em temas, técnicas e abordagens; internacionalização; apresentar levantamentos sobre o passado do campo e sua história. Novas ideias, agendas de pesquisa; proposições e críticas à prática passada, atual ou tendências futuras; levantamentos bibliográficos sistemáticos sobre teorias, temas, técnicas, contribuição e produtividade no campo, bem como contribuições para o desenvolvimento da área (novas técnicas, temas, abordagens, relevância científica, práticas de pesquisa, internacionalização e carreira como pesquisador em SI).

O período de análise escolhido está representado no Quadro 1, juntamente com os códigos e títulos dos artigos; os nomes dos seus respectivos autores e considerando o quantitativo de artigos por ano: 2010 (5 artigos); 2011 (2 artigos); 2012 (3 artigos); 2013 (2 artigos); 2014 (4 artigos); 2015 (1 artigo); 2016 (4 artigos); 2017 (4 artigos) e 2018 (3 artigos).

Quadro 1 - Artigos ADI - tema 7 dos Enanpads 2010 a 2017 e artigos ADI - tema 6 do Enanpad 2018 selecionados para análise

\begin{tabular}{|c|c|c|}
\hline ENANPAD & Códigos e títulos dos artigos publicados & Nome(s) do(s) autor(es) \\
\hline 2010 & $\begin{array}{l}\text { ADI 639: "Uma reflexão sobre a interdependência } \\
\text { entre interação e estrutura social em grounded } \\
\text { theory." }\end{array}$ & Bruno Félix Von Borell de Araújo \\
\hline 2010 & $\begin{array}{l}\text { ADI 916: "Estudos de caso em Administração da } \\
\text { Informação: uma década de história a partir dos } \\
\text { anais do ENANPAD." }\end{array}$ & $\begin{array}{l}\text { Celso de Arruda Albuquerque; } \\
\text { André de Souza Coelho Gonçalves } \\
\text { de Andrade; Luiz Antônio Joia }\end{array}$ \\
\hline 2010 & $\begin{array}{l}\text { ADI 1339: "Do off-line para o online: a netnografia } \\
\text { como um método de pesquisa ou o que pode } \\
\text { acontecer quando tentamos levar a etnografia } \\
\text { para a Internet." }\end{array}$ & Márcio Noveli \\
\hline 2010 & $\begin{array}{l}\text { ADI 2038: “Design science: uma abordagem } \\
\text { inexplorada por pesquisadores brasileiros em } \\
\text { gestão de sistemas de informação." }\end{array}$ & $\begin{array}{l}\text { José Osvaldo de Sordi; Manuel } \\
\text { Meireles; Cida Sanches }\end{array}$ \\
\hline 2010 & $\begin{array}{l}\text { ADI 2412: "Inteligência estratégica: } \\
\text { desenvolvimento de uma escala para } \\
\text { compreensão do construto." }\end{array}$ & $\begin{array}{lll}\text { Ana Cristina Fachinelli; } & \text { Cintia } \\
\text { Paese Giacomello; Jane } & \text { Rech; } \\
\text { Adriana Locatelli Bertollini } & \end{array}$ \\
\hline 2011 & $\begin{array}{l}\text { ADI 391: "Instrumento de mensuração dos tipos } \\
\text { estratégicos: uma análise comparativa no contexto } \\
\text { do alinhamento estratégico entre negócios e } \\
\text { tecnologia da informação." }\end{array}$ & $\begin{array}{l}\text { Eduardo Henrique Rigoni; } \\
\text { Norberto Hoppen }\end{array}$ \\
\hline 2011 & $\begin{array}{l}\text { ADI 1539: "Entendimento interpretativo em } \\
\text { pesquisa qualitativa sobre sistemas de } \\
\text { informação." }\end{array}$ & Gilberto Clóvis Josemin \\
\hline 2012 & $\begin{array}{l}\text { ADI 367: "Relação (in)direta entre capacidade de } \\
\text { tecnologia da informação e desempenho: suporte } \\
\text { à teoria baseada em recursos e identificação de } \\
\text { mediadores." }\end{array}$ & $\begin{array}{l}\text { Deyvison de Lima Oliveira; Gessy } \\
\text { Dhein Oliveira }\end{array}$ \\
\hline 2012 & ADI 1534: “Gestão de equipes-cliente na & Pedro Jácome de Moura Júnior; \\
\hline
\end{tabular}

Perspectivas em Gestão \& Conhecimento, João Pessoa, v. 10, n. 2, p. 180-202, maio/ago. 2020. 


\begin{tabular}{|c|c|c|}
\hline & $\begin{array}{l}\text { implantação de sistemas ERP: uma grade de } \\
\text { repertórios estruturais, cognitivos e } \\
\text { comportamentais no nordeste brasileiro." }\end{array}$ & Carlo Gabriel Porto Bellini \\
\hline 2012 & $\begin{array}{l}\text { ADI 1707: "Validação de instrumentos para } \\
\text { mensurar os fatores influenciadores na aquisição e } \\
\text { na implantação de sistemas de informação em } \\
\text { micro e pequenas empresas." }\end{array}$ & $\begin{array}{l}\text { Mauri Leodir Löbler; Eliete dos } \\
\text { Reis; Monize Sâmara Visentini; } \\
\text { Kálien Alves Klimeck }\end{array}$ \\
\hline 2013 & $\begin{array}{l}\text { ADI 502: "Representações gráficas na teoria ator- } \\
\text { rede aplicada a sistemas de informação." }\end{array}$ & $\begin{array}{l}\text { André de Souza Coelho Gonçalves } \\
\text { de Andrade; Luiz Antônio Joia; } \\
\text { Marcelo Fornazin; Gabriel } \\
\text { Marcuzzo do Canto Cavalheiro }\end{array}$ \\
\hline 2013 & $\begin{array}{l}\text { ADI 992: “A abordagem design science no Brasil } \\
\text { segundo as publicações em Administração da } \\
\text { Informação." }\end{array}$ & $\begin{array}{l}\text { José Osvaldo de Sordi; Márcia } \\
\text { Carvalho de Azevedo; Manuel } \\
\text { Meireles; Milton de Abreu } \\
\text { Campanário }\end{array}$ \\
\hline 2014 & $\begin{array}{l}\text { ADI 15: "Governança de tecnologia da informação: } \\
\text { métodos científicos nas publicações de Tecnologia } \\
\text { da Informação em Administração." }\end{array}$ & $\begin{array}{l}\text { Cláudio Márcio Campos de } \\
\text { Mendonça; Glauber Ruan Barbosa } \\
\text { Pereira }\end{array}$ \\
\hline 2014 & $\begin{array}{l}\text { ADI 638: "Como estão sendo conduzidos os } \\
\text { estudos de caso? Uma reflexão sobre os trabalhos } \\
\text { publicados na área de Administração." }\end{array}$ & $\begin{array}{l}\text { Mauri Leodir Löbler; Eliete dos } \\
\text { Reis Leinhart; Ana Flávia Andrade } \\
\text { Avelino }\end{array}$ \\
\hline 2014 & $\begin{array}{l}\text { ADI 981: "Uma visão sobre a pesquisa acadêmica } \\
\text { em Sistemas de Informação no Brasil: } 1994 \text { a } \\
\text { 2013." }\end{array}$ & $\begin{array}{l}\text { Henrique Mello Rodrigues de } \\
\text { Freitas; João Luiz Becker; Carla } \\
\text { Bonato Marcolin }\end{array}$ \\
\hline 2014 & $\begin{array}{l}\text { ADI 2286: “Análise das publicações brasileiras } \\
\text { sobre segurança da informação sob a ótica social } \\
\text { em periódicos científicos entre } 2004 \text { e 2013." }\end{array}$ & $\begin{array}{l}\text { Antônio Eduardo de Albuquerque } \\
\text { Júnior; Ernani Marques dos } \\
\text { Santos }\end{array}$ \\
\hline 2015 & $\begin{array}{l}\text { ADI 1109: "Analisando os sistemas de informação } \\
\text { e suas traduções: uma revisão sobre a teoria ator- } \\
\text { rede." }\end{array}$ & $\begin{array}{l}\text { Marcelo Fornazin; Luiz Antônio } \\
\text { Joia }\end{array}$ \\
\hline 2016 & $\begin{array}{l}\text { ADI 2308: "Inserção internacional do campo de } \\
\text { Administração da Informação (ADI): análise da } \\
\text { formação, publicação e participação em redes de } \\
\text { pesquisa." }\end{array}$ & $\begin{array}{lcc}\text { Eduardo } & \text { Henrique } & \text { Diniz; José } \\
\text { Eduardo Ricciardi } & \text { Favaretto; } \\
\text { Henrique Pontes; Débora V. } \\
\text { Richter Brólio }\end{array}$ \\
\hline 2016 & $\begin{array}{l}\text { ADI 2313: "A visão baseada em recursos nas } \\
\text { pesquisas de Sistemas de Informação no Brasil: } \\
\text { abordagens, aplicabilidade e direcionamento de } \\
\text { pesquisas." }\end{array}$ & $\begin{array}{l}\text { Antônio Carlos Gastaud Maçada; } \\
\text { José Carlos da Silva Freitas Júnior; } \\
\text { Aline de Vargas Pinto }\end{array}$ \\
\hline 2016 & $\begin{array}{l}\text { ADI 2584: "S-Commerce: um estudo na } \\
\text { perspectiva da NeurolS." }\end{array}$ & $\begin{array}{ll}\text { Alexander } & \text { Mazutti Velho; Diana } \\
\text { Adamatti; } & \text { Fernanda Antoniolo; } \\
\text { Décio } & \text { Bittencourt Dolci; } \\
\text { Guilherme Lerch Lunardi }\end{array}$ \\
\hline 2016 & $\begin{array}{l}\text { ADI 2719: "Produção científica sobre adoção de } \\
\text { tecnologia da informação: análise dos artigos } \\
\text { publicados em anais de eventos científicos } \\
\text { nacionais entre } 2011 \text { e 2015." }\end{array}$ & $\begin{array}{l}\text { Rodrigo Cesar Reis de Oliveira; Ivo } \\
\text { Pedro Gonzales Júnior; Antônio } \\
\text { Eduardo de Albuquerque Júnior; } \\
\text { Ernani Marques dos Santos }\end{array}$ \\
\hline 2017 & $\begin{array}{l}\text { ADI 755: "Grounded theory em sistemas de } \\
\text { informação: reflexões sobre sua } \\
\text { operacionalização." }\end{array}$ & $\begin{array}{l}\text { Paulo Cristiano de Oliveira; } \\
\text { Marina Keiko Nakayama }\end{array}$ \\
\hline 2017 & $\begin{array}{l}\text { ADI 1590: "Internacionalização da pesquisa em } \\
\text { Administração de Sistemas de Informação (ADI) e } \\
\text { apoio institucional: visão dos pesquisadores." }\end{array}$ & $\begin{array}{l}\text { Eduardo H. Diniz; José Eduardo } \\
\text { Ricciardi Favaretto; Henrique } \\
\text { Pontes Gonçalves de Oliveira; } \\
\text { Débora V. Richter Brólio }\end{array}$ \\
\hline
\end{tabular}

Perspectivas em Gestão \& Conhecimento, João Pessoa, v. 10, n. 2, p. 180-202, maio/ago. 2020. 


\begin{tabular}{|c|l|l|}
\hline 2017 & $\begin{array}{l}\text { ADI 1738: “Perspectiva Neuro-IS: análise } \\
\text { bibliométrica da adoção de Neurociências em } \\
\text { estudos de sistemas de informação no período de } \\
\text { 2010 a 2016." }\end{array}$ & $\begin{array}{l}\text { Mauri Leodir Löbler; Rafaela } \\
\text { Dutra Tagliapietra; Eliete dos Reis } \\
\text { Lehnhart; Carolina Schneider } \\
\text { Bender }\end{array}$ \\
\hline 2017 & $\begin{array}{l}\text { ADI 1833: "Visão do campo de Sistemas de } \\
\text { Informação sob a lente teórica das capacidades } \\
\text { dinâmicas." }\end{array}$ & $\begin{array}{l}\text { Maurício Munhoz de Medeiros; } \\
\text { Larissa Sielichoff; Caroline } \\
\text { Kretschmer }\end{array}$ \\
\hline 2018 & $\begin{array}{l}\text { ADI 1815: "Estudos críticos em SI: por uma crítica } \\
\text { a partir da realidade brasileira." }\end{array}$ & $\begin{array}{l}\text { Erica Souza Siqueira; Eduardo } \\
\text { Henrique Diniz }\end{array}$ \\
\hline 2018 & $\begin{array}{l}\text { ADI 1847: "Incentivos institucionais internos e } \\
\text { externos para internacionalização da pesquisa em } \\
\text { Administração da Informação." }\end{array}$ & $\begin{array}{l}\text { Eduardo Henrique Diniz; Henrique } \\
\text { Pontes; José Eduardo Favaretto; } \\
\text { Débora Richter Brólio }\end{array}$ \\
\hline 2018 & $\begin{array}{l}\text { ADI 2464: "Quem somos em SI? A história do } \\
\text { campo de Sistemas de Informação no Brasil." }\end{array}$ & $\begin{array}{l}\text { Gleice Fernandes Martins Dantas; } \\
\text { Aldo Leonardo Cunha Callado }\end{array}$ \\
\hline
\end{tabular}

\section{RESULTADOS E DISCUSSÃO}

De modo a contextualizar os temas 06 e 07 da Divisão Acadêmica ADI no evento Enanpad, no período em estudo (2010 a 2018), fez-se um levantamento da participação deles no número de artigos acadêmicos publicados. 0 resultado está exposto na Tabela 1:

Tabela 1 - Participação dos temas 06 e 07 da Divisão Acadêmica ADI nos Enanpads (2010 a 2018)

\begin{tabular}{cccccc}
\hline Evento/Ano & $\begin{array}{c}\text { No total de } \\
\text { artigos do } \\
\text { evento }\end{array}$ & $\begin{array}{c}\text { No total de } \\
\text { artigos da } \\
\text { Divisão } \\
\text { Acadêmica } \\
\text { ADI }\end{array}$ & $\begin{array}{c}\text { Percentual de } \\
\text { artigos da } \\
\text { Divisão } \\
\text { Acadêmica } \\
\text { ADI }\end{array}$ & $\begin{array}{c}\text { No total de } \\
\text { artigos ADI do } \\
\text { tema 07 e do } \\
\text { tema 06 (em } \\
\text { 2018) }\end{array}$ & $\begin{array}{c}\text { Percentual de } \\
\text { artigos do } \\
\text { tema 07 e do } \\
\text { tema 06 (em } \\
\text { 2018) na ADI }\end{array}$ \\
\hline Enanpad 2010 & 853 & 49 & $5,74 \%$ & 05 & $10,20 \%$ \\
Enanpad 2011 & 865 & 41 & $4,74 \%$ & 02 & $4,87 \%$ \\
Enanpad 2012 & 875 & 51 & $5,82 \%$ & 03 & $5,88 \%$ \\
Enanpad 2013 & 862 & 45 & $5,22 \%$ & 02 & $4,44 \%$ \\
Enanpad 2014 & 857 & 63 & $7,35 \%$ & 04 & $6,35 \%$ \\
Enanpad 2015 & 1043 & 56 & $5,37 \%$ & 01 & $1,78 \%$ \\
Enanpad 2016 & 1165 & 62 & $5,32 \%$ & 04 & $6,45 \%$ \\
Enanpad 2017 & 1190 & 59 & $4,95 \%$ & 04 & $6,77 \%$ \\
Enanpad 2018 & 1287 & 65 & $5,05 \%$ & 03 & $4,61 \%$ \\
\hline Total & 8997 & 491 & $5,52 \%$ & 28 & $5,70 \%$ \\
\hline \multicolumn{7}{c}{ Fonte: Anais dos Enanpads (2010-2018) }
\end{tabular}

O que foi possível observar na tabela 1 é que tanto o tema 06 (2018) quanto o tema 07 (2010 a 2017) da Divisão Acadêmica ADI apresentaram pouca produção de artigos acadêmicos que buscassem o debate sobre possíveis contribuições para as pesquisas em $\mathrm{TI} / \mathrm{SI}$, quer em termos de novas abordagens, temas e tendências; agendas e proposições de pesquisa; o futuro da área, etc. Tal fato foi possível de notar ao se observar que apenas no ano de 2010 é que se teve $10,20 \%$ dos trabalhos publicados buscando ir além da simples comprovação empírica da implementação e uso produtivo de um(a) SI/TI.

Em termos de regiões do território nacional, notou-se uma significativa presença de artigos acadêmicos oriundos das regiões sudeste e sul (Quadro 2); não por acaso, as regiões que empreenderam, na década de 1980, os primeiros esforços no sentido de consolidarem um corpo de conhecimento em SI. Isso ficou evidenciado com a origem institucional do 1 o autor e 
na qual a região sudeste apresentou 10 artigos publicados $(35,71 \%)$, enquanto a região sul teve 12 artigos (42,85\%), isto é, ambas as regiões totalizaram quase $80 \%$ de toda a produção nos temas 06 e 07 da Divisão Acadêmica ADI no evento Enanpad, no período em estudo (2010 a 2018). Ademais, percebeu-se a pequena participação $(21,44 \%)$ das regiões nordeste e norte do Brasil em termos de geração de conhecimento em $\mathrm{SI}$, o que talvez se justifique por representarem regiões com ainda pouca tradição e recursos para o desenvolvimento de pesquisas em SI.

Quadro 2 - Região nacional de origem de instituição do 10 autor de trabalho publicado na Divisão Acadêmica ADI (temas 06 e 07) dos Enanpads (2010 a 2018)

\begin{tabular}{|c|c|c|c|c|}
\hline & REGIÃO SUDESTE & REGIÃO SUL & REGIÃO NORDESTE & REGIÃO NORTE \\
\hline Enanpad 2010 & $\begin{array}{c}\text { artigos } \\
{[1(\mathrm{ES})+2(\mathrm{SP})]}\end{array}$ & $\begin{array}{c}2 \text { artigos } \\
{[1(R S)+1(P R)]}\end{array}$ & - & - \\
\hline Enanpad 2011 & - & $\begin{array}{c}2 \text { artigos } \\
{[2(\mathrm{RS})]}\end{array}$ & - & - \\
\hline Enanpad 2012 & - & $\begin{array}{l}1 \text { artigo } \\
{[1(\mathrm{RS})]}\end{array}$ & $\begin{array}{l}1 \text { artigo } \\
{[1(\mathrm{~PB})]}\end{array}$ & $\begin{array}{l}1 \text { artigo } \\
{[1(\mathrm{RO})]}\end{array}$ \\
\hline Enanpad 2013 & $\begin{array}{c}2 \text { artigos } \\
{[1(\mathrm{RJ})+1(\mathrm{SP})]}\end{array}$ & - & - & - \\
\hline Enanpad 2014 & - & $\begin{array}{c}2 \text { artigos } \\
{[2(\mathrm{RS})]}\end{array}$ & $\begin{array}{l}1 \text { artigo } \\
{[1(\mathrm{BA})]}\end{array}$ & $\begin{array}{l}1 \text { artigo } \\
{[1(\mathrm{AP})]}\end{array}$ \\
\hline Enanpad 2015 & $\begin{array}{l}1 \text { artigo } \\
{[1(\mathrm{RJ})]}\end{array}$ & - & - & - \\
\hline Enanpad 2016 & $\begin{array}{l}1 \text { artigo } \\
{[1(\mathrm{SP})]}\end{array}$ & $\begin{array}{c}2 \text { artigos } \\
{[2(\mathrm{RS})]}\end{array}$ & $\begin{array}{l}1 \text { artigo } \\
{[1(\mathrm{BA})]}\end{array}$ & - \\
\hline Enanpad 2017 & $\begin{array}{l}1 \text { artigo } \\
{[1(\mathrm{SP})]}\end{array}$ & $\begin{array}{c}3 \text { artigos } \\
{[1(\mathrm{SC})+2(\mathrm{RS})]}\end{array}$ & - & - \\
\hline Enanpad 2018 & $\begin{array}{c}2 \text { artigos } \\
{[1(\mathrm{SP})+1(\mathrm{RJ})]}\end{array}$ & - & $\begin{array}{l}1 \text { artigo } \\
{[1(\mathrm{~PB})]}\end{array}$ & - \\
\hline Total: & 10 artigos & 12 artigos & 4 artigos & 2 artigos \\
\hline
\end{tabular}

Fonte: Anais dos Enanpads (2010-2018)

Legendas:

$\mathrm{AP}=$ Amapá

$\mathrm{PR}=$ Paraná

$\mathrm{RJ}=$ Rio de Janeiro

RO=Rondônia



$\mathrm{PB}=$ Paraíba

$\mathrm{RS}=$ Rio Grande do Sul
$\mathrm{SC}=$ Santa Catarina

$\mathrm{SP}=\mathrm{São}$ Paulo

Analisando as cidades por região nacional, o Quadro 3, a seguir, apresenta aquelas que contribuíram com os artigos nos temas 06 e 07 da Divisão Acadêmica ADI no evento Enanpad, no período em estudo (2010 a 2018). Assim, na região sudeste, São Paulo (6 artigos) e Rio de Janeiro (3 artigos) tiveram destaque, enquanto na região sul o Rio Grande do Sul, sozinho, apareceu com uma produção expressiva de 10 publicações. Na região nordeste apareceram publicações apenas da Paraíba ( 2 artigos) e da Bahia ( 2 artigos), enquanto na região norte apenas publicações do Amapá (1 artigo) e de Rondônia (1 artigo). 
Quadro 3 - Cidades por região nacional do 1ㅇ autor de trabalho publicado na Divisão Acadêmica ADI (temas 06 e 07) dos Enanpads (2010 a 2018)

\begin{tabular}{|c|c|c|c|c|c|c|c|c|c|c|c|}
\hline & \multicolumn{3}{|c|}{ REGIÃO SUDESTE } & \multicolumn{3}{|c|}{ REGIÃO SUL } & \multicolumn{2}{|c|}{$\begin{array}{c}\text { REGIÃO } \\
\text { NORDESTE }\end{array}$} & \multicolumn{2}{|c|}{$\begin{array}{c}\text { REGIÃO } \\
\text { NORTE }\end{array}$} & \multirow{3}{*}{$\begin{array}{l}\begin{array}{l}\text { Total por } \\
\text { Instituição }\end{array} \\
17 \text { artigos }\end{array}$} \\
\hline & SP & RJ & ES & RS & SC & PR & PB & BA & AP & RO & \\
\hline Pública & - & $\begin{array}{c}2 \\
\text { artigos }\end{array}$ & - & $\begin{array}{c}7 \\
\text { artigos }\end{array}$ & $\begin{array}{l}1 \\
\text { artigo }\end{array}$ & $\begin{array}{c}1 \\
\text { artigo }\end{array}$ & $\begin{array}{c}2 \\
\text { artigos }\end{array}$ & $\begin{array}{c}2 \\
\text { artigos }\end{array}$ & $\begin{array}{c}1 \\
\text { artigo }\end{array}$ & $\begin{array}{c}1 \\
\text { artigo }\end{array}$ & \\
\hline Privada & $\begin{array}{c}6 \\
\text { artigos }\end{array}$ & $\begin{array}{c}1 \\
\text { artigo }\end{array}$ & $\begin{array}{c}1 \\
\text { artigo }\end{array}$ & $\begin{array}{c}3 \\
\text { artigos }\end{array}$ & - & - & - & - & - & - & 11 artigos \\
\hline $\begin{array}{l}\text { Total } \\
\text { por } \\
\text { Cidade }\end{array}$ & $\begin{array}{c}6 \\
\text { artigos }\end{array}$ & $\begin{array}{c}3 \\
\text { artigos }\end{array}$ & $\begin{array}{c}1 \\
\text { artigo }\end{array}$ & $\begin{array}{c}10 \\
\text { artigos }\end{array}$ & $\begin{array}{l}1 \\
\text { artigo }\end{array}$ & $\begin{array}{c}1 \\
\text { artigo }\end{array}$ & $\begin{array}{c}2 \\
\text { artigos }\end{array}$ & $\begin{array}{c}2 \\
\text { artigos }\end{array}$ & $\begin{array}{c}1 \\
\text { artigo }\end{array}$ & $\begin{array}{c}1 \\
\text { artigo }\end{array}$ & \\
\hline
\end{tabular}

Fonte: Anais dos Enanpads (2010-2018)

Legendas:

AP=Amapá

PR=Paraná

$\mathrm{BA}=$ Bahia

ES=Espírito Santo

$\mathrm{PB}=$ Paraíba
RJ=Rio de Janeiro

RO=Rondônia

RS=Rio Grande do Sul
$\mathrm{SC}=$ Santa Catarina

SP=São Paulo

Em termos de natureza institucional das publicações, conforme o Quadro 4 a seguir, notou-se que as instituições públicas estão presentes com as suas publicações em quase todos os anos do intervalo pesquisado, com a exceção de 2013, além de terem um quantitativo de 17 artigos publicados $(60,70 \%)$. Tal constância de presença das instituições públicas nas publicações analisadas se justifica porque os mais consolidados grupos de pesquisa em SI/TI no Brasil encontram ambiente propício à investigação acadêmica nessas instituições de natureza pública. Tal regularidade não foi possível de ser notada nas publicações das instituições privadas que estiveram ausentes nos Enanpads de 2012; 2014 e 2015 e um quantitativo total de 11 artigos publicados (39,30\%), o que possivelmente se justifica pelo fato de não existir uma política sistemática e institucionalizada de produção de conhecimento nas instituições de natureza privada.

Quadro 4 - Publicações de instituições públicas e privadas na Divisão Acadêmica ADI (temas 06 e 07) dos Enanpads (2010 a 2018)

\begin{tabular}{|c|c|}
\hline Instituição Pública & Instituição Privada \\
\hline 1 artigo ( Enanpad 2010) & 4 artigos (Enanpad 2010) \\
\hline 1 artigo (Enanpad 2011) & 1 artigo (Enanpad 2011) \\
\hline 3 artigos (Enanpad 2012) & 2 artigos (Enanpad 2013) \\
\hline 4artigos (Enanpad 2014) & 1 artigo (Enanpad 2016) \\
\hline 1 artigo (Enanpad 2015) & 2 artigos (Enanpad 2017) \\
\hline 3 artigos (Enanpad 2016) & 1 artigo (Enanpad 2018) \\
\hline 2 artigos (Enanpad 2017) & - \\
\hline 2 artigos (Enanpad 2018) & Total: 11 artigos \\
\hline Total: $\mathbf{1 7}$ artigos &
\end{tabular}

Fonte: Anais dos Enanpads (2010-2018)

\subsection{Classificação dos conhecimentos presentes nos trabalhos acadêmicos publicados segundo Hirschheim e Klein (2003)}

Tendo por referência Hirschheim e Klein (2003), buscou-se conhecer os tipos de conhecimento presentes nos artigos acadêmicos publicados no evento ENANPAD de 2010 a 
2018; especificamente os artigos tanto do tema 06 (2018) quanto do tema 07 (2010 a 2017) da Divisão Acadêmica ADI. Assim, foi possível identificar 18 artigos técnicos (64,3\%), 5 artigos teóricos (17,85\%), 5 artigos aplicados (17,85\%) e nenhum artigo normativo (ético), conforme o quadro 5 a seguir. $O$ que isso significa? Significa que parece ainda prevalecer a visão tradicional dominante do papel dos sistemas de informação como ferramentas de apoio à tomada de decisão em um contexto organizacional, pragmaticamente voltado a alcançar objetivos previamente traçados. Tal resultado pode ser reforçado pela constatação de que não houve nenhum artigo de aspecto normativo (ético) no qual é considerada a perspectiva dos participantes (ou usuários) dos sistemas de informação e seu particular contexto social e institucional.

Já os artigos teóricos identificados, alternavam-se entre a apresentação de métodos a serem adotados nos estudos da área (grounded theory, a netnografia, etc.) e abordagens possíveis de serem desenvolvidas em sistemas de informação (design science -DS, teoria atorrede, teoria da visão baseada em recursos, etc.). Por último, em termos de artigos aplicados (práticos), teve-se levantamento bibliográfico sistemático sobre contribuição e produtividade no campo de $\mathrm{SI}$, assim como prática de pesquisa (DS) em sistemas de informação e o desenvolvimento histórico do campo.

Quadro 5 - Tipos de conhecimento identificados segundo Hirschheim e Klein (2003) nos artigos da Divisão Acadêmica ADI (temas 06 e 07) dos Enanpads (2010 a 2018)

\begin{tabular}{|c|c|c|c|c|}
\hline & Técnico & Normativo (ético) & Teórico & Aplicado (prático) \\
\hline Enanpad 2010 & $\begin{array}{c}\text { ADI 916; ADI 2038; } \\
\text { ADI 2412 }\end{array}$ & - & ADI 639; ADI 1339 & - \\
\hline Enanpad 2011 & ADI 391 & - & - & ADI 1539 \\
\hline Enanpad 2012 & ADI 367; ADI 1707 & - & - & ADI 1534 \\
\hline Enanpad 2013 & - & - & ADI 502 & ADI 992 \\
\hline Enanpad 2014 & ADI 15; ADI 638; & - & - & ADI 981 \\
\hline Enanpad 2015 & - & - & ADI 1109 & - \\
\hline Enanpad 2016 & $\begin{array}{c}\text { ADI 2313; ADI 2719; } \\
\text { ADI 2584; ADI 2308 }\end{array}$ & - & - & - \\
\hline Enanpad 2017 & ADI 1833; ADI 1738; & & - & - \\
\hline ADI 1590; ADI 755 & ADI 1847 & - & ADI 1815 & ADI 2464 \\
\hline Enanpad 2018 & $\mathbf{1 8}$ artigos & - & $\mathbf{5}$ artigos & $\mathbf{5}$ artigos \\
\hline
\end{tabular}

Fonte: Anais dos Enanpads (2010-2018)

\subsection{Os aspectos metodológicos e as estratégias de pesquisa presentes nos trabalhos acadêmicos publicados}

Em termos metodológicos, observou-se que, dos 28 artigos publicados na Divisão Acadêmica ADI (temas 06 e 07) dos Enanpads (2010 a 2018), 22 artigos (78,57\%) eram empíricos e apenas 6 artigos (21,43\%) não empíricos, aqui compreendidos como ensaios ou artigos teóricos. Tal constatação está em acordo com os tipos de conhecimento identificados segundo Hirschheim e Klein (2003) porque reforça a visão de aplicação prática e pragmática com que os sistemas de informação são empregados no contexto organizacional. Reforça-se essa assertiva com a evidência de que em termos temporais, foram identificados 20 artigos $(71,43 \%)$ com corte seccional, isto é, o tema ou problema de pesquisa foram sistematicamente delimitados por um período de tempo; enquanto os artigos de aspecto longitudinal, demandando mais tempo de observação e investigação para melhor conhecer o tema ou problema de pesquisa, representavam apenas 8 artigos publicados $(28,57 \%)$.

Perspectivas em Gestão \& Conhecimento, João Pessoa, v. 10, n. 2, p. 180-202, maio/ago. 2020. 
A análise metodológica dos artigos estudados ainda mostrou que, dos 28 artigos publicados, 14 tiveram abordagem qualitativa (50\%), enquanto apenas 7 tiveram abordagem quantitativa (25\%) e outros 7 artigos utilizaram a abordagem quali-quantitativa (25\%), conforme o Quadro 6 a seguir. Conforme evidenciado em outros estudos sobre a produção científica em SI (TEIXEIRA JÚNIOR, 2002; ROSSINI; HOCAYEN-DA-SILVA, 2007; ZIMMER; FERREIRA; HOPPEN, 2007; MOTA; MARQUES, 2013; ALBUQUERQUE JÚNIOR; SANTOS, 2014), há o predomínio de estudos qualitativos na área de SI. Isso parece indicar uma significativa mudança uma vez que em um estudo realizado em 2004 com 189 artigos da Divisão Acadêmica ADI no evento Enanpad, compreendendo o período de 1997 a 2003, identificou-se o predomínio quase absoluto da abordagem quantitativa, com apenas 7 artigos (3,70\%) identificados com a abordagem qualitativa (FELL; XIMENES; RODRIGUES FILHO, 2004).

Quadro 6 - Abordagens metodológicas adotadas nos artigos da Divisão Acadêmica ADI (temas 06 e 07) dos Enanpads (2010 a 2018)

\begin{tabular}{|c|c|c|c|}
\hline & Quantitativa & Qualitativa & Quanti-Qualitativa \\
\hline Enanpad 2010 & ADI 916; ADI 2412 & $\begin{array}{c}\text { ADI 639; ADI 1339; ADI } \\
2038\end{array}$ & - \\
\hline Enanpad 2011 & ADI 391 & ADI 1539 & - \\
\hline Enanpad 2012 & ADI 367 & - & ADI 1534; ADI 1707 \\
\hline Enanpad 2013 & - & ADI 502 & ADI 992 \\
\hline Enanpad 2014 & ADI 638 & ADI 981 & ADI 15; ADI 2286 \\
\hline Enanpad 2015 & - & ADI 1109 & ADI 2719 \\
\hline Enanpad 2016 & ADI 2308 & ADI 2313; ADI 2584 & ADI 1738 \\
\hline Enanpad 2017 & ADI 1590 & ADI 1833; ADI 755 & - \\
\hline Enanpad 2018 & - & ADI 1815; ADI 1847; & ADI 2464 \\
\hline 4 Total: & & $\mathbf{1 4}$ artigos & artigos \\
\hline
\end{tabular}

Fonte: Anais dos Enanpads (2010-2018)

Em termos de estratégias de pesquisa, notou-se uma concentração de mais de $60 \%$ dos artigos publicados na Divisão Acadêmica ADI (temas 06 e 07) dos Enanpads (2010 a 2018) em apenas cinco tipos: ensaio (21,43\%), estudo bibliométrico (17,85\%), survey $(10,71 \%)$, revisão sistemática+bibliométrico $(10,71 \%)$ e estudo de casos múltiplos $(7,14 \%)$, conforme o quadro 7 a seguir. Uma possível explicação está na própria natureza do tema 07 (2010 a 2017) e tema 06 (2018) da ADI dos Enanpads estudados. Em outros termos, tem-se uma Divisão Acadêmica denominada "Visão do campo e aspectos teóricos e metodológicos em $\mathrm{TI} / \mathrm{SI}$ " que está voltada não apenas para averiguar o que já se faz/fez ou o que se pensa na área de $\mathrm{SI}$, quer em termos aplicados ou conceituais; mas também se dispõe discutir novos temas, abordagens, ideias técnicas e agendas de pesquisa que possam sinalizar em que direção vai a área de SI. 
Quadro 7 - As estratégias de pesquisa presentes nos artigos da Divisão Acadêmica ADI (temas 06 e 07) dos Enanpads (2010 a 2018)

$*$ Ensaio $\rightarrow 6$ artigos publicados $(21,43 \%)$

* Estudo bibliométrico $\rightarrow 5$ artigos publicados $(17,85 \%)$

* Survey $\rightarrow 3$ artigos publicados (10,71\%)

* Revisão sistemática + bibliométrico $\rightarrow 3$ artigos publicados $(10,71 \%)$

* Estudo de casos múltiplos $\rightarrow 2$ artigos publicados $(7,14 \%)$

* Estudo experimental $\rightarrow 1$ artigo publicado $(3,58 \%)$

* Dados secundários $\rightarrow 1$ artigo publicado $(3,58 \%)$

* Relato de experiência $\rightarrow 1$ artigo publicado $(3,58 \%)$

* Não identificado/não informado $\rightarrow 6$ artigos publicados (21,43\%)

Fonte: Anais dos Enanpads (2010-2018)

\subsection{Categorização e análise epistemológica dos trabalhos acadêmicos publicados}

Analisando os aspectos epistemológicos dos artigos presentes nos anais dos Enanpads de 2010 a 2018, a partir de Orlikowski e Baroudi (1991), notou-se o predomínio do paradigma positivista, com 17 artigos publicados $(60,7 \%)$, seguido do paradigma interpretativo com 10 artigos publicados $(35,7 \%)$ e um único artigo do paradigma crítico $(3,6 \%)$, conforme apresentado no quadro 8 a seguir. Tal constatação parece indicar a ainda forte influência positivista na área de SI nos encontros da ANPAD no qual o racionalismo organizacional reflete "a visão tradicional dominante do papel dos sistemas de informação como apoio ao processo de tomada de decisão em um contexto organizacional que busca alcançar objetivos" (FELL; XIMENES; RODRIGUES FILHO, 2004, p.3).

Contudo, há que se ressaltar a marcante presença do paradigma interpretativo nos artigos analisados de 2010 a 2018, uma vez que Fell, Ximenes e Rodrigues Filho (2004) analisando 189 artigos da Divisão Acadêmica ADI no evento Enanpad, compreendendo o período de 1997 a 2003, identificaram apenas 7 artigos (3,70\%) do paradigma interpretativo há apenas 15 anos atrás.

Quadro 8 - Aspectos epistemológicos identificados segundo Orlikowski e Baroudi (1991) nos artigos da Divisão Acadêmica ADI (temas 06 e 07) dos Enanpads (2010 a 2018)

\begin{tabular}{|c|c|c|c|}
\hline & Positivista & Interpretativo & Crítico \\
\hline Enanpad 2010 & $\begin{array}{c}\text { ADI 916; ADI 2038; ADI } \\
2412\end{array}$ & ADI 639; ADI 1339 & - \\
\hline Enanpad 2011 & ADI 291 & ADI 1539 & - \\
\hline Enanpad 2012 & $\begin{array}{c}\text { ADI 367; ADI 1534; ADI } \\
1707\end{array}$ & - & - \\
\hline Enanpad 2013 & ADI 992 & ADI 502 & - \\
\hline Enanpad 2014 & $\begin{array}{c}\text { ADI 15; ADI 638; ADI } \\
2286 \\
\end{array}$ & ADI 981 & - \\
\hline Enanpad 2015 & - & ADI 1109 & - \\
\hline Enanpad 2016 & $\begin{array}{c}\text { ADI 2313; ADI 2584; } \\
\text { ADI } 2308\end{array}$ & ADI 2719 & - \\
\hline Enanpad 2017 & $\begin{array}{c}\text { ADI 1833; ADI 1738; } \\
\text { ADI } 1590\end{array}$ & ADI 755 & - \\
\hline Enanpad 2018 & - & ADI 1847; ADI 2464 & ADI 1815 \\
\hline Total: & 17 artigos & 10 artigos & 1 artigo \\
\hline
\end{tabular}

Perspectivas em Gestão \& Conhecimento, João Pessoa, v. 10, n. 2, p. 180-202, maio/ago. 2020. 


\section{CONCLUSÕES}

Não parece haver mais dúvidas de que a adoção de Tecnologias da Informação (TI) pode afetar positivamente o desempenho organizacional, uma vez que pode melhorar a sua competitividade, produtividade e eficiência (HAMEED; COUNSELL, 2012); possibilitando-Ihe maiores chances de sobrevivência em mercados cada vez mais globalizados (SAFAVI; AMINI; JAVADINIA, 2014). Ocorre, no entanto, que a comunidade acadêmica de sistemas de informação tem tido dificuldades em efetivamente comunicar quais são os principais conceitos de sua área e porque estes conhecimentos são importantes (IVES et al., 2002; BELLINI; DANTAS; PEREIRA, 2013).

Em um esforço de minimizar esse hiato, buscou-se nessa pesquisa avaliar o estado da arte do campo de conhecimento de SI no Brasil, a partir da análise dos trabalhos publicados nos anais do ENANPAD (2010 a 2018). Em termos mais específicos, buscou-se compreender de que modo as pesquisas realizadas no campo de SI no Brasil vêm se desenvolvendo nos seus aspectos teóricos, metodológicos e epistemológicos.

Em termos teóricos foi possível observar uma diversidade de perspectivas teóricas (design science -DS, teoria ator-rede, teoria da visão baseada em recursos, etc.) sendo aplicadas ao campo de $\mathrm{SI}$, a partir dos artigos acadêmicos publicados no evento ENANPAD de 2010 a 2018. Uma possível explicação para isso é que a área contempla uma gama de pesquisadores com múltiplas origens como ciência da computação, administração, física, química, matemática, psicologia entre outras. Como resultado, tem-se um pluralismo não apenas teórico, conceitual, mas também metodológico (GREGOR, 2006).

Ainda em termos metodológicos, houve o predomínio de artigos empíricos $(78,57 \%)$ com relação aos não empíricos (21,43\%); refletindo, ainda hoje, que o modo como ocorreu o processo de introdução da área de SI no Brasil foi por intermediação de dois grandes eixos: o acadêmico e o organizacional (prático) (DANTAS; CALLADO, 2018). A abordagem de pesquisa mais adotada foi a qualitativa, presente em 14 artigos acadêmicos analisados (50\%); indicando uma mudança, não necessariamente estrutural, mas que pode sinalizar novas tendências em oportunidades de pesquisa, temas e técnicas - algo pouco esperado para o campo de SI há algumas décadas atrás (ORLIKOWSKI; BAROUDI, 1991; CIBORRA, 2002; POZZEBON, 2003; FELL; XIMENES; RODRIGUES FILHO, 2004). Pela própria natureza do tema 07 (2010 a 2017) e tema 06 (2018) da ADI dos Enanpads estudados, as estratégias de pesquisa se concentraram mais em cinco tipos: ensaio $(21,43 \%)$, estudo bibliométrico $(17,85 \%)$, survey $(10,71 \%)$, revisão sistemática+bibliométrico $(10,71 \%)$ e estudo de casos múltiplos $(7,14 \%)$.

Por último, em termos epistemológicos, ainda é bem significativa a presença do paradigma positivista $(60,7 \%)$ nos artigos nacionais analisados, o que pode indicar ainda alguma resistência ao uso de métodos interpretativos em SI como, por exemplo, o método hermenêutico dialético, ou a hermenêutica crítica (HC), de Myers (1995), que constitui uma junção de hermenêutica com a teoria crítica de Habermas e que servem para entender as falhas na implementação de sistemas de informação; ou ainda, o uso da análise crítica do discurso, usando Habermas (Cukier et al., 2009), para avaliar as relações de poder e interesse moldando o discurso sobre a tecnologia. O campo de SI, como fenômeno social, tem muito a ganhar com o questionamento crítico dos aspectos técnicos e funcionalistas do SI como científico/Hard e a valorização de teorias sociais que auxiliem no estudo da dimensão social de SI (visão Soft) e que, por conseguinte, põem em xeque a forma hegemônica do paradigma positivista no campo de SI. Outras significativas contribuições, por exemplo, podem trazer o interpretativismo crítico de Doolin (1998) que propôs a combinação da tradição de pesquisa interpretativista de estudos em SI com a teoria de Poder de Foucault e que, por meio dessa combinação, tem-se a viabilidade de uma perspectiva crítica interpretativista, ao permitir-se

Perspectivas em Gestão \& Conhecimento, João Pessoa, v. 10, n. 2, p. 180-202, maio/ago. 2020. 
analisar a capacidade de agência e de resistência à implantação e uso de um novo SI, isto é, ser possível abrir a caixa preta das relações de poder.

\section{REFERÊNCIAS}

ALAVI, M.; CARLSON, P.; BROOKE, G. The ecology of MIS research: a twenty year review. In: DeGROSS, J.I; HENDERSON, J.C.; KONSYNSKI, B.R. (Eds.). Proceedings of the Tenth International Conference on Information Systems, p.363-375, 1989.

ALBUQUERQUE JÚNIOR, A.E.; SANTOS, E.M. Análise das publicações brasileiras sobre segurança da informação sob a ótica social em periódicos científicos entre 2004 e 2013. In: ENCONTRO DA ANPAD, 38., Rio de Janeiro/RJ, 2014.

AVGEROU, C. Information systems: what sort of science is it? Omega - The International Journal of Management Science, n. 28, p. 567-579, 2000.

AVGEROU, C.; SIEMER, J.; BJORN-ANDERSEN, N. The academic field of information systems in Europe. European Journal of Information Systems, v. 8, n. 2, p. $136-153,1999$.

BACKHOUSE, J.; LIEBENAU, J.; LAND, F. On the discipline of information system. Journal of Information Systems, 1 (1), 19 - 27, 1991.

BAKOS, J. Y; NAULT, B. R. Ownership and investment in electronic networks. Information Systems Research, v. 8, n. 4, p. 321-341, 1997.

BANKER, R.; KAUFFMAN, R. Quantifying the business value of information technology: an illustration of the 'business value linkage' framework (NYU working paper no. IS-91-21). New York: New York University, 1991.

BARUA, A.; MURKHOPADHYAY, T. Information technology and business performance: past, present and future. In: ZMUD, R.W. (Ed.). Framing the domains of IT research: projecting the future through the past (p. 65-84). Cincinnati: Pinnaflex Educational Resources, 2000.

BARUA, A.; KRIEBEL, C.; MULHOPADHYAYM T. Information technology and business value: an analytic and empirical investigation. Information Systems Research, v. 6, n. 1, p. 3-23, 1995.

BELLINI, C.; DANTAS, G.; PEREIRA, R. Are we still talking to ourselves: an analysis of the introspective information technology field by Brazilians experts. International Journal of Human Capital and Information Technology Professionals, v. 4, n. 3, p. 11-25, 2013.

BENBASAT, I.; ZMUD, R. The identity crisis within the IS discipline: defining and communicating the discipline's core properties. MIS Quarterly, v. 27, n. 2, p. 183-194, 2003.

BENBASAT, I.; ZMUD, R. Empirical research in Information Systems: the practice of relevance. MIS Quarterly, v. 23, n. 1, p. 3-16, 1999.

BENBASAT, I.; WEBER, R. Rethinking diversity in information systems research. Information Systems Research, v. 7, n. 4, p. 389-399, 1996.

BENBASAT, I.; ZMUD, R. Empirical research in information systems: the practice of relevance. MIS Quarterly, v. 23, n. 1, p.3-16, 1999. 
BJORN-ANDERSEN, N. Challenge to certainty. In: BEMELMANS, T. (ed.). Beyond productivity: information systems development for organizational effectiveness. Amsterdam: NorthHolland, 1984.

BLUMENTHAL, S. C. Management information systems: a framework for planning and development. Englewood Cliffs: Prentice-Hall, 1969.

BOLAND, R. Phenomenology: a preferred approach to research in Information Systems. In: MUMFORD, E.; HIRSCHHEIM, R.A.; FITZGERALD, G.; WOODHARPER, T. (eds.). Research Methods in Information Systems, NorthHolland, Amsterdam, p. 193201, 1985.

CHECKLAND, P.; HOLWELL, S. Information, systems and information systems - making sense of the field. Chichester: John Wiley \& Sons, 1998.

CIBORRA, C. The labyrinths of information: challenging the wisdom of systems. Oxford: Oxford University Press, 2002.

CUKIER, W.; NGWENYAMA, O.; BAUER, R.; MIDDLETON, C. A critical analysis of media discourse on information technology: preliminary results of a proposed method for critical discourse analysis. Information Systems Journal, v. 19, n. 2, p.175-196, 2009.

CULNAN, M. Mapping the intellectual structure of MIS, 1980-1985: a co-citation analysis. MIS Quarterly, v. 11, n. 3, p. 341-353, 1987.

CULNAN, M. The intellectual development of management information systems, 1972-1982: a co-citation analysis. Management Science, v. 32, n. 2, p.156-172, 1986.

CULNAN, M.; SWANSON, E. B. Research in management information systems, 1980-1984: points of work and relevance. MIS Quarterly, v. 19, n. 3, p. 289-302, 1986.

DANTAS, G. F. M.; CALLADO, A.L.C. Quem somos em SI? A história do campo de Sistema de Informação no Brasil. In: 42 Encontro da ANPAD, Curitiba/PR, 2018.

DAVIS, L.; OLSON, M. Management information systems: conceptual foundations, structure and development. New York: McGraw-Hill, 1985.

DAVIS, G. Information systems conceptual foundations: looking backward and forward. In: BASKERVILLE, R.; STAGE, J.; DEGROSS, J. (eds.). Organizational and social perspectives on information technology. Boston: Kluwer Publishers, 2000. p.61-82.

DAVIS, G. Management Information Systems. New York: McGraw-Hill, 1974.

DEMARCO, T. Structured analysis and systems specification. New York: Yourdon Press, 1978.

DINIZ, E.H.; PETRINI, M.; BARBOSA, A.F.; CHRISTOPOULOS, T.P.; SANTOS, H.M. Abordagens epistemológicas em pesquisas qualitativas: além do positivismo nas pesquisas na área de sistemas de informação. In: ENCONTRO da ANPAD, 30., 2006, Salvador. Cd-rom...Salvador/BA: ANPAD, 2006.

DOOLIN, B. Information technology as disciplinary technology: being critical in interpretive research on Information Systems. Journal of Information Technology, 1998.

FELL, A.F.A.; XIMENES, A.F.; RODRIGUES FILHO, J. Pesquisa qualitativa em sistemas de informação (S.I.) no Brasil: uma análise da produção acadêmica. In: SIMPÓsIO DE ENGENHARIA DE PRODUÇÃO (SIMPEP), 11., 2004. São Paulo. Anais [...]. São Paulo, 2004. 
GALLIERS, R. Change as crisis of growth? Towards a trans-disciplinary view of information systems as a field of study. Journal of the Association for Information Systems, 4(6), 337 351, 2003.

GANE, C.; SARSON, T. Structured systems analysis: tools and techniques. Englewood:Cliffs. Prentice Hall, 1979.

GORRY, G.; SCOTT-MORTON, M. A framework for management information systems. Sloan Management Review, 12 (1), 55-70, 1971.

GREGOR, S. The nature of theory in Information System. Management Information Systems Quarterly, v.3, n.3, p.611-642, 2006.

HAMEED, M.A.; COUNSELL, S. Assessing the influence of environmental and CEO characteristics for adoption of information technology in organizations. Journal of Technology Management \& Innovation, 7(1), 64-84, 2012.

HEVNER, A.R.; BERNDT, D.J.; STUDNICKI, J. Strategic information systems planning with box structures. Paper presented at the IEEE Proceedings of the 33rd Hawaii International Conference on Systems Science, Hawaii, 2000.

HIRSCHHEIM, R.; KLEIN, H.K. Crisis in the IS field? A critical reflection on the state of the discipline. Journal of the Association for Information Systems, 4 (5), 237-293, 2003.

HIRSCHHEIM, R.; KLEIN, H.K. A glorious and not-so-short history of the Information System field. Journal of the Association for Information Systems, v.13, issue 4, p.188-235, April 2012.

HITT, L.; BRYNJOLFSSON, E. Productivity, profit and consumer welfare - three different measures of information technology's value. MIS Quarterly, v. 20, n. 2, p. 1-23, 1996.

HOPPEN, N.; MEIRELLES, F.S. Sistemas de informação: um panorama da pesquisa científica entre 1990 e 2003. Revista de Administração de Empresas - RAE, 45(1), 24-35, 2005.

HOPPEN, N.; et. al. Sistemas de informação no Brasil: uma análise dos artigos científicos dos anos 90. In: ENCONTRO DA ANPAD, 22., Foz do Iguaçu/PR, 1998.

IVES, B.; VALACICH, J.; WATSON, R.T.; ZMUD, R.; et. al. What every business student needs to know about Information Systems. Communications of the Association for Information Systems, v.9, p. 467-477, 2002.

IVES, B.; HAMILTON, S.; DAVIS, G. A framework for research in computer-based management information systems. Management Science, 26 (9), 910 - 934, 1980.

KAPLAN, B., MAXWELL, J.A. Qualitative research methods for evaluating computer information system. In: J.G. ANDERSON, J.G.; AYDIN, C.E.; JAY, S.J. (eds.) Evaluating Health Care Information Systems: methods and applications. Sage, Thousand Oaks, CA, pp.45-68, 1994.

KAUFFMAN, R.J.; KRIEBEL, C.H. Modeling and measuring the business value of information technology. In: ICIT Research Study Team (Eds.). Measuring the Business Value of Information Technologies. Washington, DC; ICIT Press, 1988.

KEEN, P. Relevance and rigor in information systems research: improving quality, confidence, cohesion and impact. In: NISSEN, H.E.; KLEIN, H.K.; HIRSCHHEIM, R. (Eds.). Information systems research: contemporary approaches and emergent traditions (pp. 27-49). Amsterdam: NorthHolland, 1991.

Perspectivas em Gestão \& Conhecimento, João Pessoa, v. 10, n. 2, p. 180-202, maio/ago. 2020. 
KEEN, P. MIS research: current status, trends and needs. In: BUCKINGHAM, R.; HIRSCHHEIM, R.; LAND, F.; TULLY, C. (eds.), Information Systems Education: recommendations and implementation (pp. 1-13). Cambridge: Cambridge University Press, 1987.

KEEN, P. MIS research: reference disciplines and cumulative tradition. In: MCLEAN, E. (Ed.). Proceedings of the First International Conference on Information Systems, Philadelphia, 17 31, 1980.

KING, J.L.; MYERS, M.; RIVARD, S.; SAUNDERS, C.; WEBER, R. What I like about the IS discipline. Communications of the AIS, 26, 441-450, 2010.

KING, J.L.; LYYTINEN, K. (Eds.). Information systems: the state of the field. Chichester: John Wiley \& Sons, 2006.

KLEIN, H.K.; HIRSCHHEIM, R. The structure of the IS discipline reconsidered: implications and reflections from a community of practice perspective. Information \& Organization, 18 (4), 280302, 2008.

KRISHNA, S. Crisis in the information systems discipline: a reflection. SSRN Electronic Journal, pp. 132-141, 2007.

LAND, F. Evaluation of systems goals in determining a design strategy for a computer-based information system. The Computer Journal, 19 (4), 290 - 294, 1975.

LANGEFORS, B. Information systems. Information Processing 74. Amsterdam: North-Holland, 1974.

LEE, A.S. Rigor and relevance in MIS research: beyond the approach of positivism alone. MIS Quarterly, vol.23, n. 1, pp. 29-34, 1999.

LEE, A.S. Integrating positivist and interpretive approaches to organizational research. Organization Sciences, vol. 2, n. 4, pp. 342-365, 1991.

LUCAS, H.C. The state of the information systems field. Communications of the AIS, 5 (1), 1-6, 1999.

MAHMOOD, M.; MANN, G. Measuring the organizational impact of information technology investment: an explanatory study. Journal of Management Information Systems, 10 (1), 97122, 1993.

MARKUS, M.L. Thinking the unthinkable: what happens if the IS field as we know it goes away? In: Currie, W; Galliers, R. (Eds). Rethinking MIS. Oxford: Oxford University Press, 1999.

MARKUS, M.L. The qualitative difference in information systems research and practice. In: LEE, A.; LIEBENAU, J.; DEGROSS, J. (Eds.). Information systems and qualitative research. London: Chapman \& Hall, 1997.

MASON, R.; MITROFF, I. A program for research on management information systems. Management Science, 19 (5), 475 - 487, 1973.

MOTA, A.F.; MARQUES, E.V. Governança da Tecnologia da Informação: um estudo bibliométrico no período de 2007 a 2012. In: ENCONTRO ENADI DA ANPAD, 4., 2013. Bento Gonçalves/RS, 2013.

MYERS, M.D. Dialectical hermeneutics: a theoretical framework for the implementation of information systems. Information Systems Journal, 5(1), 51-70, 1995. 
NOLAN, R.L.; WETHERBE, J.C. Toward a comprehensive framework for MIS research. MIS Quarterly, 4(2), 1-19, 1980.

ORLIKOWSKI, W.; BAROUDI, J. Studying information technology in organizations: research approaches and assumptions. Information Systems Research, 2 (1), 1-28, 1991.

POPPER, K. Conjectures and refutations: the growth of scientific knowledge. London: Harper \& Row, 1969.

POZZEBON, M. Criteria for conducting and evaluating critical interpretive research in the IS field. Cahier du GreSI, no 3 (14). Décembre, 2003.

RADEMACHER, R. The changing profile of Information Systems Research: 1995 - 2001. Journal of Computer Information Systems, vol. 42, pp. 1, pp. 13-16, 2001.

ROACH, S.S. The case of the missing technology payback. Paper presented at the Tenth International Conference on Information Systems, Boston, MA, 1989.

ROACH, S.S. Technology and the service sector: America's hidden competitive advantage. In: GUILE, B; QUINN, J.B. (Eds.). Technology in services (pp. 125-145). Washington, DC; National Academy Press, 1988.

ROBEY, D. Diversity in information systems research: threat, promise and responsibility. Information Systems Research, 7 (4), 400-408, 1996.

RODRIGUES FILHO, J.; et. al. O paradigma interpretativo na pesquisa e desenvolvimento de sistemas de informação. Conferência da Business Association of Latin American Studies (BALAS), New Orleans, 1999.

ROSSONI, L.; HOCAYEN-DA-SILVA, A.J. Administração da Informação: a produção científica brasileira entre 2001 e 2006. In: ENCONTRO DA ANPAD, 31., 2007. Rio de Janeiro/RJ, 2007.

SAFAVI, N.S.; AMINI, M.; JAVADINIA, S.A. The determinant of adoption of enterprise resource planning for small and medium enterprises in Iran. International Journal of Advanced Research in IT and Engineering, 3(1), 1-8, 2014.

STRASSMANN, P. The information payoff: the transformation of work in the electronic age. New York: The Free Press, 1985.

TAN, M.; TEO, T.S.H. Factors influencing the adoption of internet banking. Journal of the Association for Information Systems, 1(5), 1-42, 2000.

TEIXEIRA JÚNIOR, F. Análise dos métodos de pesquisa utilizados em artigos de Administração da Informação: levantamento de artigos publicados nos Enanpads de 1999 a 2001. In: ENCONTRO DA ANPAD, 26. Salvador/BA, 2002.

WALSHAM, G. The emergence of interpretivism in IS research. Information Systems Research. Vol. 6 (4): 376-394, 1995.

WAND, Y.; WEBER, R. Toward a theory of the deep structure of information systems. In: DEGROSS, J.; ALAVI, M.; OPPELLAND, H. (Eds.). Proceedings of the Eleventh International Conference on Information Systems, Copenhagen, 61 - 71, 1990.

WEBER, R. Still desperately seeking the IT artifact. MIS Quarterly, v. 27, n. 2, p. iii-xi, 2003. 
ZIMMER, M.V.; FERREIRA, L.; HOPPEN, N. Validação e confiabilidade em pesquisas na área de Sistemas de Informação: uma análise os artigos publicados no Enanpad entre 1998 e 2006. In: ENCONTRO DA ANPAD, 31., Rio de Janeiro/RJ, 2007.

Artigo recebido em 23/01/2020 e aceito para publicação em 02/05/2020 